\title{
Effect on Mechanical Properties of Heat Treated High Manganese Austenitic Cast Iron
}

\author{
A.K. Muzafar ${ }^{1,}{ }^{*}$, M.M. Rashidi ${ }^{1}$, I. Mahadzir ${ }^{1}$, and Z. Shayfull ${ }^{2}$ \\ ${ }^{1}$ Faculty of Mechanical Engineering, Universiti Malaysia Pahang, 26600 Pekan, Pahang, Malaysia. \\ ${ }^{2}$ School of Manufacturing Engineering, Universiti Malaysia Perlis, Kampus Tetap Pauh Putra, 02600 \\ Arau, Perlis Malaysia.
}

\begin{abstract}
This work presents an attempt to study the effect of manganese addition and heat treatment on higher carbon austenitic cast iron to form high manganese austenitic cast iron with reduced nickel content (Mn-Ni-resist) on mechanical properties. The combination on microstructure (microsegregation), mechanical properties and the relationship of heat treatment on the alloy were analyzed. For this purpose Mn-Ni-resist (4.50C, 2.64Si, 6.0 Mn, 10 $\mathrm{Ni}$ ) was melted and cast in the form of Y-block test pieces. Four different heat treatment procedures were applied to the as-cast to investigate the effect of alloy modifications on Mn-Ni-resist. Optical and scanning electron microscopies were used for microstructure investigation. To determine the mechanical properties tensile test and hardness test were carried out. The result indicates both composition and heat treatment affect the performance of Mn-Ni-resist intensively. Microprobe analysis shows some silicon segregation near the graphite and practically little segregation of manganese. The increase in manganese contents developed some fractions of segregated carbide structures in LTF region located at austenite eutectic cell frame, which caused the tensile properties to drop in a small range. Application of annealing heat treatment gradually changed the carbide formation, so is the material's strength.
\end{abstract}

\section{Introduction}

Recently, researchers have shown an increased interest in austenitic cast iron study. Due to constant demand for high performances materials austenitic cast iron has been chosen for various engineering applications as substituted material to steel, as it offer an outstanding combination of properties in withstanding the effects of corrosion, heat and wear [1-5].

The high composition of austenitic matrix in microstructure is contributed by the influence of nickel contained in the composition that acts as austenite matrix promoter [6]. According to ASTM standard, with nickel composition $13.5 \mathrm{wt} \%$ up to $36 \mathrm{wt} \%$, it already manages to produces full austenitic structure in the microstructure [7, 8]. However Fatahalla et. al (2009) claims that with only $13.5 \mathrm{wt} \%$ was enough to produce austenitic

\footnotetext{
* Corresponding author: mrashidi@ump.edu.my
} 
ductile iron [1] while to produce austenitic ductile cast iron need at least $18 \mathrm{wt} \% \mathrm{Ni}$. This special alloy will be in austenitic matrix when at high temperature and also at room temperature which makes it successful avoid matrix volume changes. Despite its advantages, the used of nickel as main austenite promoter suffers from major drawbacks associated to its high price production.

Generally, the use of cast iron with high nickel content is technically as well as economically inexpedient. It can be successfully replaced nickel in austenitic cast iron with higher manganese or copper content. Since copper and manganese also can acts as austenitic promoter. Usually, austenitic cast iron with manganese addition is complexly alloyed, together with the austenitic base the structure strongly tend to produce carbide $\left(\mathrm{Mn}_{23} \mathrm{C}_{6}\right)$ through the microstructure [9] while austenitic cast iron with copper addition improves corrosion resistance in mildly acid solution and also interfere with the magnesium treatment used to produce spheroidal graphite [10]. Furthermore, it is also believed that manganese is better austenite promoter than copper [11]. At present, Mn was used solely for alloying purposes to improve DNR impact toughness property instead of austenitic matrix stabilizer and does not contribute to the reduction use of Ni. Only few of publications on optimize the use of manganese in Ni-resist. Up to date, there is no generally accepted classification of austenitic manganese cast iron in international specification standard like ASTM or ISO.

There are several attempts to utilize the use of manganese as austenitic promoter in producing Ni-resist and also using heat treatment to obtain the austenitic microstructure. The use of nickel in Ni-resist can be reduced to the range of 8-10 wt \% with assistance of 3$4 \mathrm{wt} \%$ of manganese with good properties of ductile. This finding was supported by recent investigation by Rashidi and hasbullah [12] which is studied about the effect of manganese $(10 \mathrm{wt} \%, 8-11 \mathrm{wt} \% \mathrm{Mn})$ on ductile iron with optimization of inoculation to reduce the carbide formation while Janus and Kurzawa [13] made some effort in investigate effect of nickel equivalent on austenite transition ratio in $\mathrm{Ni}-\mathrm{Mn}-\mathrm{Cu}$ cast iron using heat treatment with manganese and copper content with low austenite stability. However, investigation does not stop here, there are improvement field still open for new discovery on reducing production prices for austenitic ductile iron by manipulating the alloying element and heat treatment and microstructure. It is of interest to work out and study types of cast iron in which the austenite is stabilized by manganese.

From the previous literature, using high manganese content in Ni-resist was invited carbide formation as has been found and recorded in since the early of 1900 by Mckay [14]. Carbide formation very undesirable and was normally avoided in foundry. There are two different approaches can be used to obtain carbide free iron. The first approach would be to avoid carbide precipitation during solidification. This can be achieved by maximizing the efficiency of inoculation. Good inoculation technique managed to reduce carbide precipitation during solidification and improves its mechanical properties. The second approach would be to eliminate the carbide precipitated during solidification by means of a dissolution heat treatment.

It is technically difficult to obtain graphite of such favorable shape in Mn-Ni-resist as in gray or high-strength cast iron, especially with high carbon content. If austenitic cast iron is to find widespread application in industry, its properties and structure must be further investigated because these kinds of cast iron are very promising materials. They are cheap because they are alloyed with the abundantly available manganese, and they have valuable technological and operational properties. The present investigation was therefore an attempt undertaken to examine the influence of manganese and annealing heat treatment to discover the effect on mechanical properties. This research will concentrate on producing austenitic cast iron with high manganese content iron and application of annealing procedure on it. Tensile tests were performed to determine if the deformation-induced 
transformation was strain-induced; fracture toughness tests were performed to see if the transformation was stress-induced.

\section{Experimental procedure}

\subsection{Material preparation}

The studied alloy was prepared in a $100 \mathrm{~kg}$-capacity frequency induction furnace. Initial charge materials were pig iron, pure nickel, steel scrap, Ferro manganese and austenitic iron returns. Then the materials heated until molten state. Alloying elements such as 99.0 $\mathrm{wt} \%$ pure nickel and fe- $45.0 \mathrm{wt} \% \mathrm{Mn}$ were added to the molten alloy so as to increase and control Ni and Mn percentage content respectively. The mould was made by using Y block shaped pattern with minimum thickness of $30 \mathrm{~mm}$ was prepared by using a pattern as in

Fig according to ASTM standard for austenitic cast iron $[7,8]$ in the green sand mould. Inoculation process with $0.5 \mathrm{wt} \% \mathrm{Fe}-\mathrm{Si}$ was introduced to melt by using late inoculation in the mould technique $[4,15,16]$.

This procedure ensures that the inoculation level high and reduce magnesium fading phenomena during casting. The chemical composition of casting product was shown in Table 6.

Table 6. Chemical composition (wt.\%) of the base metal

\begin{tabular}{|c|c|c|c|c|c|c|}
\hline Elements & $\mathbf{C}$ & $\mathbf{S i}$ & $\mathbf{N i}$ & $\mathbf{M n}$ & $\mathbf{S}$ & $\mathbf{F e}$ \\
\hline Composition wt.\% & 4.5 & 1.81 & 10.00 & 4.98 & 0.082 & balance \\
\hline
\end{tabular}
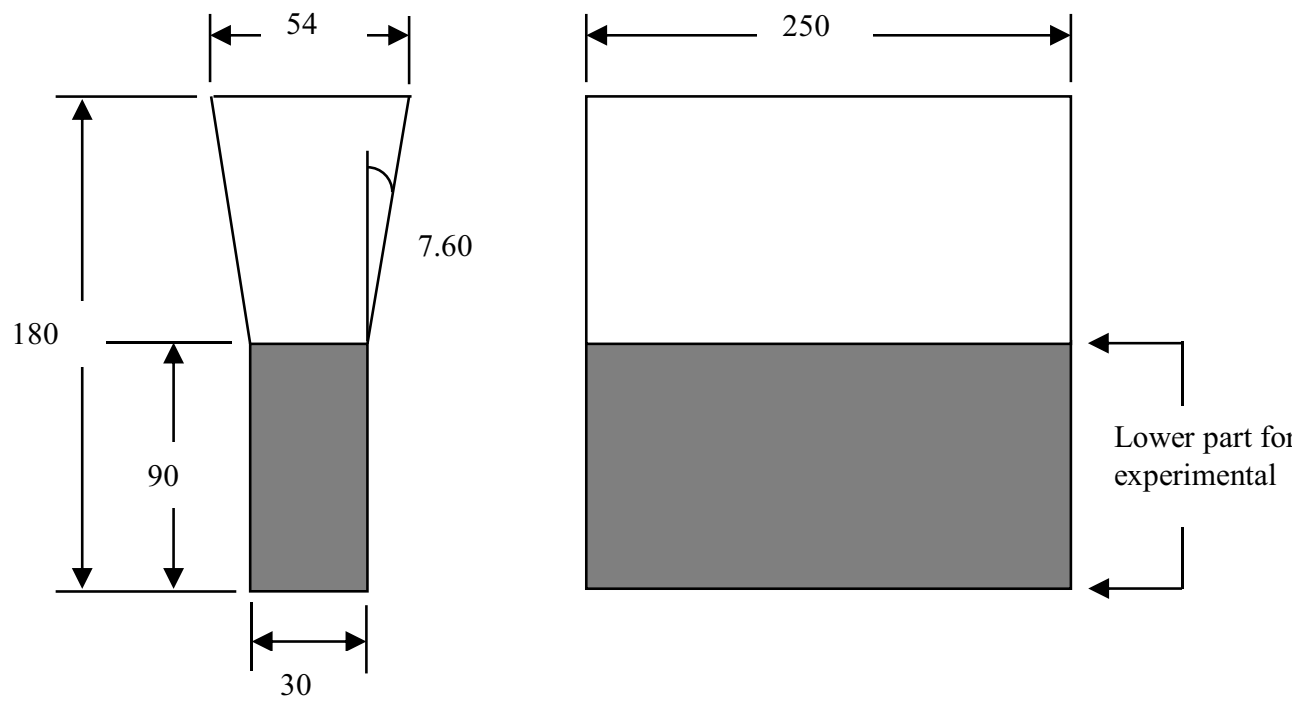

Fig. 9. Dimensions of the Y-block castings used in this experiment. Test specimens cut and machined from the lower part of the Y-block (dimensions in $\mathrm{mm}$ ). 


\subsection{Heat treatment process}

The heat treatment schedule outlined in Table 7 was carried out. All dog bone samples then were placed in a box-type resistance furnace heated according to its annealing temperature for annealing and $927^{\circ} \mathrm{C}$ for quenching. The holding time is 3 hours was counted when it reached the desired temperature. Austenitizing time less than 2 hour was not selected because the complete transformation of the as-cast structure into austenite required at least 2 hours [17]. Annealing process Annealing was held at $700^{\circ} \mathrm{C}, 800^{\circ} \mathrm{C}, 900^{\circ} \mathrm{C}$ and $1000^{\circ} \mathrm{C}$ for $3.0 \mathrm{~h}$. Then the samples cooled down to room temperature by furnace cooling respectively. For the purpose of easy analysis, as shown in Table 7, every heat treatment process was named according to its annealing temperature and heat treatment condition.

Due to slight oxidation of the surface of cast iron, there is every possibility of scale formation on this surface during transfer of the samples to the oil tank or cooling to room temperature and making the hardness and tensile value vary. Moreover, the specimen will not also be gripped properly in the machine. The specimens were polished to remove the scales from the surface to avoid these difficulties.

\subsection{Mechanical test}

Tensile test were carried out using universal testing machine $50 \mathrm{kN}$ was used according to American Society of the International Association for Testing and Materials standard ASTM E8/E8M [18] at room temperature. CNC lathe machine was used to shape the cast alloy specimen to produce dog bone shape as shown in Fig. 10. The samples were further examined using scanning electron magnetic (SEM) to assess the microstructure after fracture. Samples from the specimens of $700^{\circ} \mathrm{C}, 800^{\circ} \mathrm{C}, 900^{\circ} \mathrm{C}$ and $1000^{\circ} \mathrm{C}$ soaking temperature were taken for the hardness test. The Brinell hardness test machine was used to determine the macro hardness. Five reading was taken from each sample and averaged.

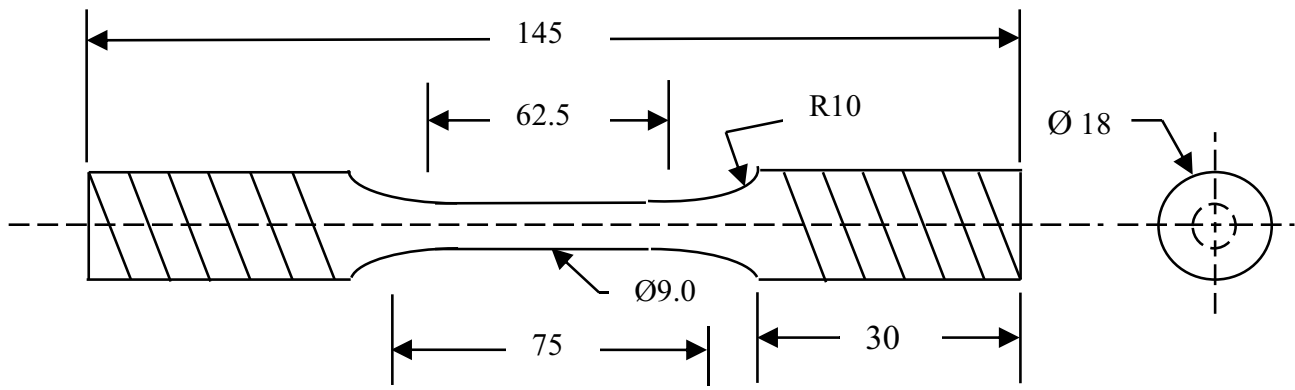

Fig. 10. Dimension of tensile test specimen.

\subsection{Microstructure analysis}

The metallographic analysis of the specimens was carried out in the round shaped specimen obtained from the broken halves of the tensile specimen. Metallographic samples were sectioned, ground and polished with 1 to $6 \mu \mathrm{m}$ grade diamond paste, rinsed in distilled water and degreased with ethanol. The etch solution of 3\% Nital was used for investigation of microstructure of samples. The microstructure was examined using optical microscope $(\mathrm{OM})$ and scanning electron microscope (SEM) next analyzed using images analyzer ImageJ [19]. 
Table 2. Chemical composition of raw material

\begin{tabular}{|l|c|c|c|c|c|c|c|c|c|c|c|}
\hline \multirow{2}{*}{ Material } & \multicolumn{10}{|c|}{ Elements (wt. \%) } \\
\cline { 2 - 14 } & $\mathbf{C}$ & $\mathbf{S i}$ & $\mathbf{M n}$ & $\mathbf{P}$ & $\mathbf{S}$ & $\mathbf{M g}$ & $\mathbf{N i}$ & $\mathbf{C a}$ & $\mathbf{C r}$ & $\mathbf{R . E}$ & $\mathbf{F e}$ \\
\hline Pig iron & 4.5 & 1.73 & 0.309 & 0.180 & 0.150 & 0.310 & 0.236 & - & - & - & balance \\
\hline Steel & 0.19 & 0.15 & 0.54 & 0.90 & 0.02 & - & - & - & - & - & balance \\
\hline Nickel & - & - & - & - & - & - & 99.0 & - & - & - & balance \\
\hline FeMn & - & - & 86.00 & - & - & - & - & - & - & - & - \\
\hline Inoculant & - & 70.00 & - & - & - & - & - & 2.0 & - & - & balance \\
\hline
\end{tabular}

\section{Result and discussion}

\subsection{Tensile properties}

Table 7 demonstrates the influence of heat treatment and annealing temperature in the range from $700^{\circ} \mathrm{C}$ to $1000^{\circ} \mathrm{C}$ in tensile properties of $\mathrm{Mn}-\mathrm{Ni}$ austenitic cast iron for all heats. It is apparent from the table that when annealing temperature was introduced, ultimate tensile strength and elongation was increasing as well. This is probably due to a decreases of carbide phase amount at LTF region between graphite which restructuring itself by influenced of elevated temperature during annealing. Another possible explanation of the resulted phenomenon would be more scattered carbide in free form smaller in size situated in LTF region in contrast with as-cast condition. This claim was reiterated by Felon (1993) that heat treatment results in precipitation of small carbides and can reduce the proof strength values [20]. It is supposed to solidifies as big size carbide as shown in Fig. 12. Most probably smaller carbide situated at LTF region propagated less crack during load applied. Thus the tensile result is much better. Hence, this will encourage slightly higher tensile characteristic that responsible for the overall material strength.

Table 7. Mechanical properties of high manganese austenitic cast iron

\begin{tabular}{|l|c|c|c|}
\hline \multirow{2}{*}{\multicolumn{1}{|c|}{ Materials }} & \multicolumn{3}{|c|}{ Room temperature test } \\
\cline { 2 - 4 } & $\begin{array}{c}\text { Ultimate tensile } \\
\text { strength (MPa) }\end{array}$ & $\begin{array}{c}\text { Elongation } \\
(\%)\end{array}$ & Macro hardness (HRB) \\
\hline As-cast & 60.10 & 1.04 & 102.53 \\
\hline Annealing $700^{\circ} \mathrm{C}$ & 66.67 & 1.14 & 100.93 \\
\hline Annealing $800^{\circ} \mathrm{C}$ & 66.63 & 1.34 & 93.63 \\
\hline Annealing $900^{\circ} \mathrm{C}$ & 71.76 & 1.74 & 90.48 \\
\hline Annealing $1000^{\circ} \mathrm{C}$ & 75.03 & 1.92 & 80.55 \\
\hline
\end{tabular}

Fig. 11 (a)(b) illustrates clearly the graph trend of the result recorded in Table 7. It is evident that material which was annealed was relatively gaining higher tensile strength (75.03 MPa) compared to as-cast condition (60.10 MPa). It is cannot be argued that higher value of Mn-Ni-resist tensile strength is well related to its annealing temperature by controlling its carbide formation. This result supported the previous report in microstructure analysis [21] as lesser carbide formation with higher annealing temperature. 
so less carbide formation with increase annealing temperature successful increase the mechanical properties compare to $\mathrm{Mn}-\mathrm{Ni}$-resist in as-cast condition.

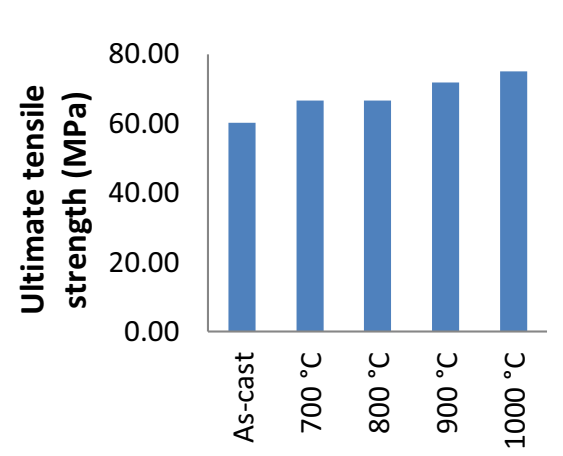

(a)

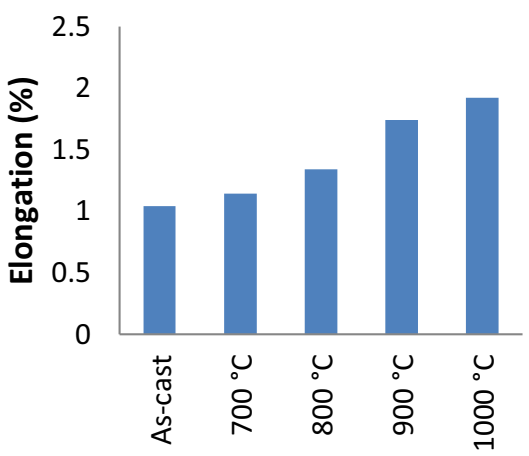

(b)

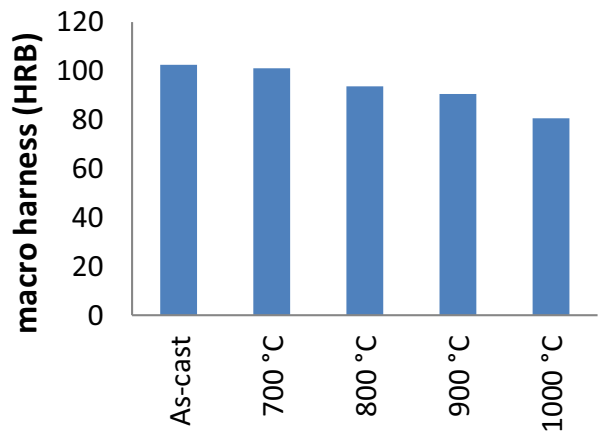

(c)

Fig. 11. Comparison of tensile properties and macro-hardness of the alloyed iron: (a) ultimate tensile strength, (b) elongation, (c) hardness

Apart from that, the influence of elements solid solution (manganese in particular) in alloyed iron which affected its mechanical properties could treat by annealing process. As a result both strength and elongation was increased. Higher annealing temperature influencing the tendency of carbide in Last to Freeze (LTF) region to form scattered. LTF crystallisation condition is different compared to mother iron liquid, where manganese as positive segregation elements concentrated more in bigger quantity. Elemental segregation influencing solidification structure which later effects solid phase transformation. Thus it is possibly exerts important effects on the mechanical properties.

\subsection{Hardness test}

Fig. 11 illustrates the influence of varying annealing temperature on hardness values in all of samples. This curve reveals that hardness is slightly decreased with increasing in annealing temperature. The highest value of hardness is for the $700^{\circ} \mathrm{C}$ sample corresponding to the large fraction of carbide in its structure compared to other samples. While the lowest hardness reading (sample $1000^{\circ} \mathrm{C}$ ) shows its carbide content is much lower in the matrix, resulting in lower macro-hardness. It can be suggested that the macrohardness of the alloyed iron is primarily affected upon addition of the heating temperature and phase constituent in the microstructure. According to ASTM-A436 standard the 
hardness values for Ni-resist (Type 1) have been reported in the range of 131 up to 149 Brinell. In this study, the hardness values were in the range of 80 up to 101 Brinell for annealed samples. It seems the relationship between the tensile properties and macrohardness of alloyed iron is shown that good annealing heat treatment practice evidently results in decreasing hardness values and increase tensile properties. It is advocates that the formation of carbide due to element segregation governs for the most part the average macro-hardness obtained.

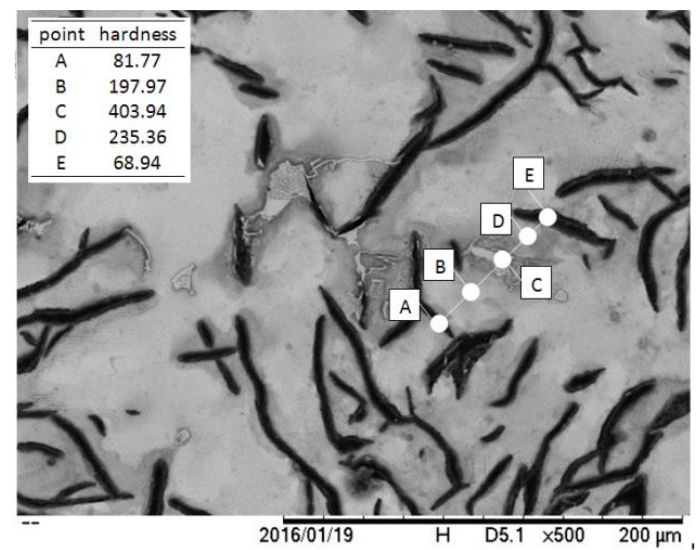

Fig. 12. Micro hardness values in the microstructure.

Fig. 12 shows the differences in micro hardness in an alloyed iron microstructure. The existence of $\mathrm{Mn}_{23} \mathrm{C}_{6}$ in the sampling microstructure explained the greater differences in the micro-hardness value discovered. $\mathrm{Mn}_{23} \mathrm{C}_{6}$, found at the last to freeze (LTF) region, has the highest micro-hardness value, averaging at $400 \mathrm{HB}$ and above as illustrate in Error! Reference source not found. The behavior of the micro-hardness value is due to segregation of the element factor where positive segregation factors such as manganese accumulated more. Manganese strongly tends to form bonding with carbon to precipitate as carbide. This proves by the highest quantitative value of micro-hardness value in this region. It developed into a complete altered phase compared to the austenitic structure around the graphite area. The low micro-hardness at area between carbide area and graphite is contributed by accumulation of negative segregation factors such as nickel and silicon which developed the austenitic structure when alloyed with Ferum. The micro hardness value for this region was reduced by approximately $50 \%$ compared to the carbide region.

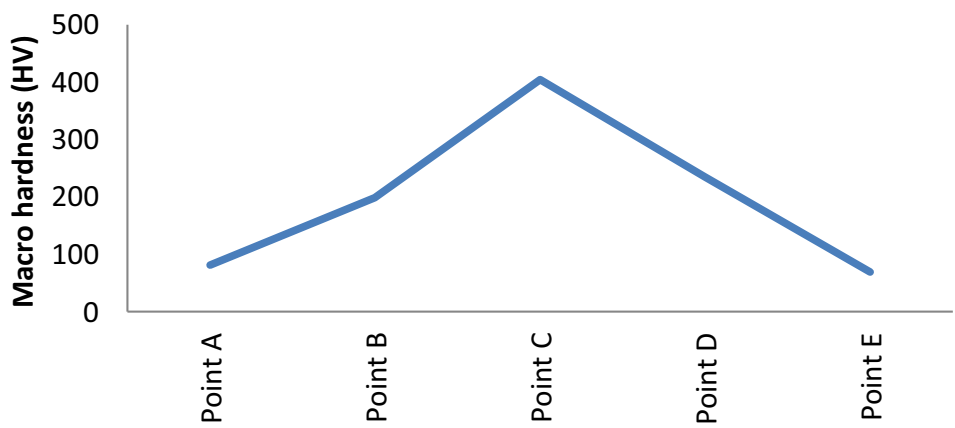

Fig. 5. Micro-hardness. 


\section{Conclusion}

Base on the above results and discussion, the following conclusions are done:

- Formation of carbide due to element segregation of manganese in inter graphite region throughout microstructure.

- Increasing the annealing temperature increase tensile strength and lowering hardness value.

- $\quad 700^{\circ} \mathrm{C}$ has the lowest tensile test properties but highest macro hardness while $1000^{\circ} \mathrm{C}$ evidently has the highest tensile strength with lowest macro hardness.

- Higher hardness is seen for the sample having higher carbide volume in the matrix.

- There is possibility that annealing temperature minimize the carbide segregation existence in alloyed iron. Segregation is the prime factor that influenced precipitation of carbide and mechanical properties.

The authors would like to express his sincere thanks to Universiti Malaysia Pahang (UMP) and ministry of education (Malaysia) for providing laboratory facilities and financial assistance under project no. RDU 140135.

\section{References}

1. N. Fatahalla, A. AbuElEzz, M. Semeida, Mater. Sci. Eng., A 504, 81 (2009)

2. Y.L. Yang, Z.Y. Cao, Z.S. Lian, H.X. Yu, Adv. Mater. Res., 194-196, 95 (2011)

3. A. Janus, K. Granat, Arch. Civ. Mech. Eng., 14, 602 (2014)

4. M.M. Rashidi, I.M. Hasbullah, Mater. Sci. Eng., A, 597, 395 (2014)

5. Alabbasian, F., S.M.A. Boutorabi, S. Kheirandish, Mater. Sci. Eng., A 651, 467 (2016)

6. R.D. Forrest, Foundry Trade J. Int., 5, 138 (1983)

7. ASTM A436, (ASTM Int., 2001)

8. ASTM A439, (ASTM Int., 2001)

9. M.M. Rashidi, I.M. Hasbullah, Mater. Des., 51, 861 (2013)

10. R. Covert, Nickelinstitute.org, (Nicle Institute, 1998)

11. G.J Cox, Foundryman., 81, 453 (1988)

12. M.M. Rashidi, and I.M. Hasbullah, Mater. Sci. Eng., A 574, 226 (2013)

13. A. Janus, A.K., 13, 53 (2013)

14. R.J. McKay, Ind. Eng. Chem., 28, 1391 (1936)

15. T. Skaland, ELKEM ASA Research. (1999)

16. M. Chisamera, I. Ripson, S. Stan, E. Stefan, G. Costache, China Foundry 6, 145 (2009)

17. S.K. Putatunda, Mater. Des., 24, 435-443, (2003)

18. ASTM E8/E8M, A., (ASTM Int., 2001)

19. C.A. Schneider, W.S. Rasband, K.W. Eliceiri, Nat. Methods, 9, 671 (2012)

20. M. Fallon, BCIRA Tech., 9315, 8 (1998)

21. M.M. Rashidi, I.M. Hasbullah, Z. Shayfull, Key. Eng. Mater., 594-595, 98 (2013) 